He was taken to hospital and did not recover consciousness for five days.

When he came to, he noticed that he could not open his left eye. There was no other paralysis but he was told that he had had a temporary left sided hemiplegia for the first three days. He noticed that when he lifted the left upper lid with his hand he saw double, The diagnosis was fracture of base of skull, nasal bones and lett jaw with left-sided third nerve paralysis.

When seen on January 20,1947, we found as follows :-

Left eye closed, but he could lift the lid very slightly with the aid of the frontalis. Vision $6 / 6$ in each eye.

Left pupil larger than right and fixed to light and convergence.

With the right eye looking straight forward and the left lid lifted manually (Fig. 1) the left eye was seen to be directed directly outwards. The corneal reflexes were on the same horizontal level.

On directing his right vision to the extreme right the left eye came to the mid-line. No other movement of the left eye was possible except in-torsion on asking the patient to look down. Both fundi were normal,

\title{
WAREN TAY-SACHS DISEASE IN A CHINESE INFANT*
}

\author{
B Y \\ Gopal Haridas \\ (FROM THE CIVIL GENERAL HOSPITAL, SINGAPORE)
}

A surver of all the available literature on Tay-Sachs disease fails to reveal evidence of the record of a case previously from Malaya. I am thus submitting a full report of a case, which was admitted to the General Hospital, Singapore-the first case of its kind occurring in Malaya in a non-Hebrew infant-together with a brief review of the clinical types, history and symptomatology which $\mathbf{I}$ believe will not prove repetitious in spite of the extensive and controversial literature that has already been written on this subject.

Tay-Sachs disease is the infantile form of amaurotic family idiocy. Amaurotic family idiocy is a type of progressive cerebral degeneration which comes under the large group of the cerebroretinal syndromes of the heredo-degenerative type. The following most modern classification of the clinical types of the cerebroretinal syndromes of the heredo-degenerative type is given in the British Encyclopaedia of Medical Practice, Volume III :- 
1. Tay-Sachs Disease (Infantile amaurotic idiocy).

2. Batten-Mayou Disease (Juvenile amaurotic idiocy).

3. Late Infantile Cerebro-Retinal Degeneration.

4. Late Juvenile Cerebro-Retinal Degeneration.

5. Anomalous Types.

(a) Tay-Sachs Disease without typical macular appearance.

(b) Batten-Mayou Disease with the cherry-red spots.

(c) Amaurotic idiocy without amaurosis.

\section{Histological summary}

In 1881, Waren Tay, an English ophthalmic surgeon, examined a 12-month-old male baby who was brought to him because he was unable to hold up his head and to move his limbs. At first, he made a provisional diagnosis of defective cerebral development and later examined the fundi. The examination revealed in the yellow spot in each eye in Tay's words " a conspicuous tolerably defined, large white patch more or less circular in outline and showing in its centre a brownish-red circular spot, contrasting strongly with the white patch surrounding it." Tay pointed out that this red spot was not due to haemorrhage or pigmentation but seemed to be due to thinning of the retina, thus forming a small hole or gap in the white patch which exposed the vascular choroid. When he examined the infant $4 \frac{1}{2}$ months later, the macular appearances were unchanged but the optic discs which were first normal had become atrophic. The child had also become helpless and died when he was 20 months old. Subsequently three more male cases were observed by him in the same family and they died before the age of two years.

In 1887, Bernard Sachs of New York published a full report of a case of a peculiar form of idiocy associated with blindness. Later, a much younger sister of this patient also became similarly affected. The fresh brain at post-mortem was found to be unusually hard and the knife actually grated on removing a small section of the cortex. A histological examination of the cut cortex showed the protoplasm of the pyramidal cells to be in various stages of degeneration.

In 1894, Kingdon pointed out that Tay's description of the ocular changes and Sachs' description of the nervous manifestations both formed the important features of one and the same disease and in the same year Carter drew attention to the fact that the disease was confined to the Jews. In 1896, Sachs named the condition amaurotic family idiocy, and the name Tay-Sachs was suggested by Higier in 1901 .

In 1909, Schaffer studied the histo-pathology of this diseas: 
in great detail. He characterised the minute pathology as an unusual swelling of the cell protoplasm and the dendrites. The interfibrillar material is first attacked and the cell degeneration follows. There results degeneration of every cell of the central grey matter of the brain, spinal cord and spinal ganglia and of the ganglion cells of the retina. There is attenuation of the nerve-fibre laver. The nerve cells later become filled with a granular prelipoid material. Schaffer concludes by expressing the opinion that children with amaurotic family idiocy possess "an abnormally exhaustive nerve-cell protoplasm, which, becoming paralysed with the strain of earliest functions, soon degenerates."

As the result of a few most important observations and elaborate microscopical examinations made by Poynton, Parsons and Gordon Holmes (1906), and by Mínt (190\%), the following conclusions were arrived at by them :-

(1) That amaurotic family idiocy is a primary disease of the nervous elements and that the proliferation of neuroglia is secondary to this.

(2) That it is a primary cell disease because the nerve-cells are relatively more affected than the fibres.

(3) That the primary change is in the interfibrillary part.

They also concluded that :-

(a) The disease was not due to arrested development because the srmptoms were not present from birth.

(b) The disease was not due to bacterial toxins.

(c) The disease was due to some inherent biochemical changes in the protoplasm of the cell which led to its degeneration.

Recently histo-pathologists have shown that this disease is one of a group of primary metabolic disorders which leads to an accumulation of lipoid substances, chiefly phosphatides in the nerve cells of the brain and ganglion cells of the retina.

\section{Aetiology}

Nothing definite is known of the cause of this affection. Syphilis, tuberculosis, alcoholism and neurotic taint play no part in its production. Infection has been excluded. It has been definitely established that it is a familial and racial disease. The occurrence? of 111 cases in 69 families containing two or more members and the presence of consanguinity in the parents in more than :) per cent. has brought out the recessive character of the condition. There is undoubtedly a greater incidence of this disease among the children of the Jewish race, especially the Jews of Poland and Russia, probably because consanguineous marriage is common 
among this race. Slome (1933) has traced 18 undoubtedly nonJewish cases among the 200 or so reported in the literature. The case I am about to describe is a Chinese Hylam infant. A few cases have also been noted among the natives of Japan. Kamel Yacoub (1938) has reported five cases of Tay-Sachs disease, all in one Egyptian family.

\section{Symptomatology of a typical case}

The " clinical picture" of Tay-Sachs disease is so characteristic that when once seen it will never be forgotten. The infant is normal when born and develops normally up to the third or sixth month. $\mathrm{He}$ then becomes listless and apathetic and no longer seems to take notice of objects. As the weakness increases he is unable to sit up. The neck muscles are weak and his head falls backwards or forwards if unsupported. There is a progressive diminution of vision and the eyes wander aimlessly about. He is susceptible to sounds. There is optic atrophy and the cherry-red spot surrounded by a lighter halo at the macula. The limbs now become rigid, the arms are extended and rotated inwards at the shoulder, the legs are extended, adducted and crossed. The knee-jerks at this stage are usually exaggerated and the plantar reflex may give an extensor response. The cerebro-spinal fluid is normal. Wasting gradually becomes extreme. The hands become flexed and contracted. The feet become extended; the knee-jerks at this stage may be difficult to obtain. The infant lies in a semi-conscious condition, convulsions may occur and a squint may be present. If the infant is fed nasally he may be kept alive for some months in an emaciated condition. Death takes place from pneumonia or quite suddenly from cardiac failure.

\section{Relation of Tay-Sachs disease to Niemann-Pick disease}

The pathological changes in Tay-Sachs disease may serve as a basis of an opinion as to the relationship of this condition to Niemann-Pick disease. In 1928, R. Hamburger observed the occurrence of Tay-Sachs disease in a case of Niemann-Pick disease. In 1928, Bielschowsky made a histological study of a case and drew attention to this association of which a number of instances have been reported.

Niemann-Pick disease is a rare condition usually met with in Jewish children. Symptoms appear within a few weeks or months after birth. The spleen is considerably enlarged, the liver becomes enlarged and the infant becomes wasted and pale. Death occurs before the end of the second year.

Histological examination of the liver and spleen shows the presence of large " foam cells" distended with a yellowish lipoid. 
Similar cells are also found in the bone-marrow, suprarenal cortex and lymphatic glands, while the ganglion cells of the nervous system may be stuffed with lipoid. It is said that this lipoid in the ganglion cells does not represent the product of degeneration of the nerve-cell, but a faulty general metabolism with fat deposited in the nervous tissues. There is a striking similarity in the chemical composition of the abnormal cell contents in the liver in Niemann-Pick disease and of the brain in Tay-Sachs disease. Pick, Spielmeyer, Bielschowsky and Kufs have expressed the belief that Tay-Sachs disease has as its basis the same metabolic disturbance. However, in Tay-Sachs disease there is localisation of the general disturbance to the central nervous system alone. But Baker and Platou as the result of pathological findings in a case of amaurotic family idiocy they studied, are not inclined to agree with above view that Tay-Sachs disease and NiemannPick disease are related. They are inclined to agree with Schaffer (1935) that Tay-Sachs disease is an endogenous condition involving ectodermal elements and is not related to Niemann-Pick disease. Schaffer says that in Tay-Sachs disease there results a primary degenerative condition with swelling of nerve cells which later become filled with a granular pre-lipoid material and that Niemann-Pick disease was the result of a metabolic disorder. Von Bogaert's observation of cases of Tay-Sachs and of Niemann-Pick diseases, in the same family, is strong evidence in favour of similar pathology in these two diseases.

In addition to the symptoms already described, a large proportion of cases show mental degeneration, spastic paralysis, fits and blindness, in short the symptoms of amaurotic family idiocy and further the pathology of the nervous system in both diseases is identical. It seems probable that Niemann-Pick disease and amaurotic family idiocy are merely different clinical expressions of one and the same condition.

\section{Report of the Case}

Register No. : 464/40. Hoo See Ngee, a male Chinese Hylam infant, aged $17 \frac{1}{2}$ months, was admitted to the Children's Ward, General Hospital, Singapore, on March 3, 1940, at 11.30 a.m. with a history of convulsions off and on for 4 months.

History: The infant was delivered normally at full term. History regarding consanguinity was not obtained because the parents never came back to see the infant after it was admitted into hospital. The infant is the fourth child in the family. The eldest child, a male, is healthy and his intelligence is normal. The other two children are dead and the cause of their death is not known. The infant was brought to hospital because he had been having fits for the last four months. He had been breast-fed for 
three months after birth and then he was condensed-milk-fed. Rice water was given for some time. The child had been able to move his limbs, cry and recognise objects and mother up to four months before admission-that is until he was $13 \frac{1}{2}$ months old. He has never been able to sit up by himself but he could be made to sit up when supported by pillows. The mother said that the infant became less and less active as days passed on and up till four months ago she did not notice anything abnormal except that he was unable to sit up.

Examination.-He weighed $16 \mathrm{lbs} .14 \mathrm{ozs}$. on admission. He appeared pale and wasted. The circumference of his head was 46 cms. His head was large. He lay in bed listless and apathetic and took no notice of his surroundings. He did not follow a bright light and he took no notice of the feeding bottle. His eyes when opened were noticed to wander aimlessly about. His eyebrows were devoid of hair. He made occasional involuntary sucking movements with his lips. His mouth was kept open with everted lips.

Objects placed in his hand were not grasped. He could not take feeds from the bottle because he would not suck at the bottle. He would not swallow milk and medicines given with the spoon but they would only accumulate in the mouth. They had to be administered by means of the nasal catheter.

He lay in whatever position he had been made to lie without making the slightest attempt to move his limbs or turn on either side. The muscles were flaccid and toneless and the limbs were slightly rigid. One could occasionally notice some movements of the fingers of the right hand but the limbs as a whole were paralysed. The deep reflexes were exaggerated and the plantar reflex was flexor.

If he was made to sit up his head fell forward. He was sensitive to noises.

An examination of the fundus with the ophthalmoscope conducted under chloroform anaesthesia by Dr. A. D. Williamson, the ophthalmic physician and surgeon, General Hospital, revealed marked pallor of both discs, a somewhat oval dark purplish-red spot at macular areas (about $\frac{1}{4}$ size of disc) on a milky bluish-white background about three times area of disc.

An X-Ray examination of the skull, conducted by Dr. J. W. Winchester, Radiologist, General Hospital, Singapore, showed that the fontanelles were widely opened and that there was no direct evidence of tumour.

Progress: The infant used to have frequent attacks of convulsions. His head gradually became bigger-size of head on 


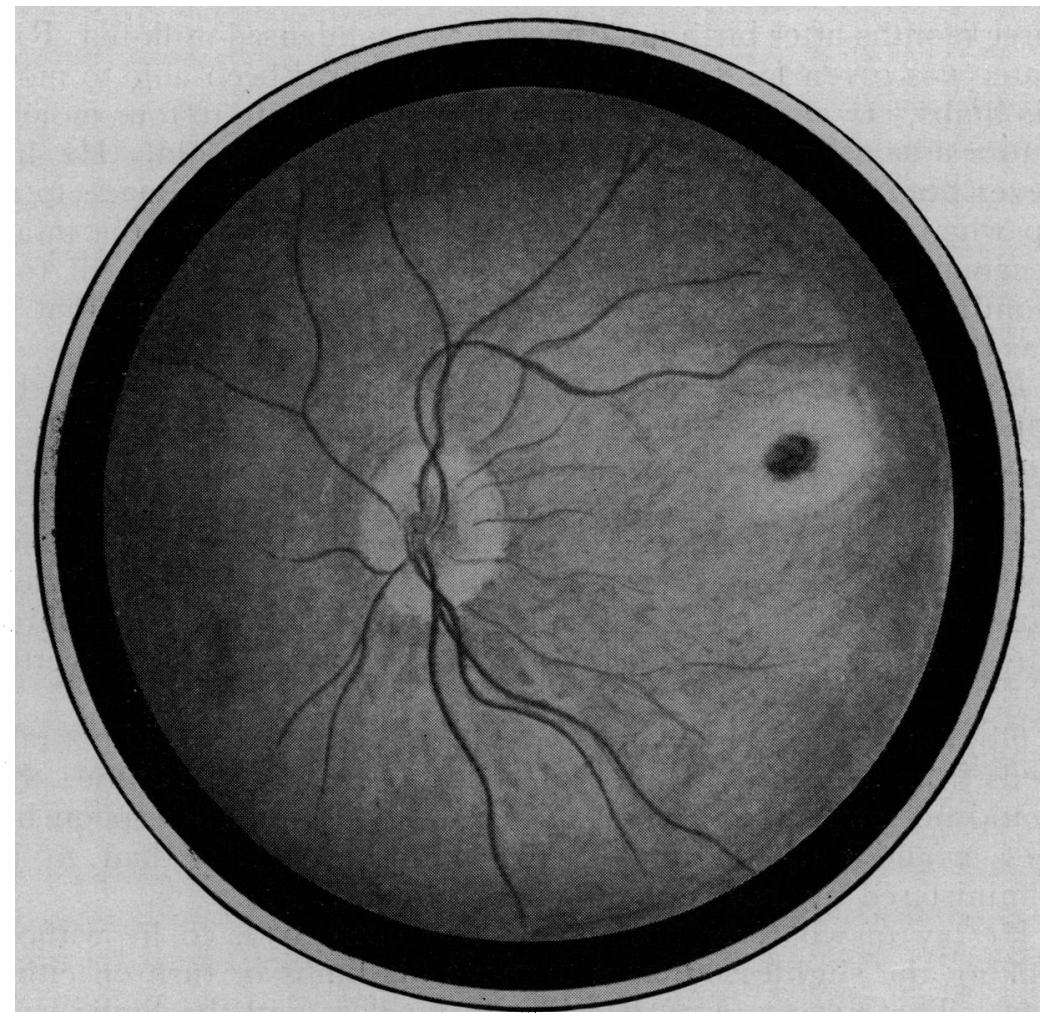

Marked pallor of both discs; a somewhat oval dark purplish-red spot at macular areas (about $\frac{1}{\mathbf{a}}$ size of disc) on a milky bluish-white background about three times area of disc.

March 3 was $46 \mathrm{~cm}$. and on May 23 was $49.8 \mathrm{~cm}$.-indication of a rapidly increasing hydrocephalus; on May 23 anterior fontanelle measurements

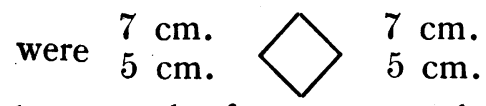

On March 12 he had an attack of acute naso-pharyngitis and on March 15 he had enteritis. He got cured of these two conditions. On March 21 he developed a cellulitis of the scalp which gradually became worse.

Muscular wasting progressed to an extreme degree. The limbs became more rigid and all the deep reflexes were exaggerated. The arms were extended and rotated inwards at the shoulder, the legs were extended, adducted and crossed. The hands became flexed and contracted and the feet extended. There were numerous pressure sores all over the body. He had been kept alive by nasal feeding. He developed pneumonia and died of it on June 8, 1940, 
that is when he was 20 months and 20 days old. An autopsy was performed but the autopsy notes are not available.

Laboratory examinations.-Blood cholesterol $186 \mathrm{mgm}$. per cent.; Blood Kahn Test Neg. (000); cerebro-spinal fluid Wassermann reaction Neg.; Cerebro-spinal fluid clear, not under pressure, nothing else abnormal.

Treatment: Antuitrins 1 c.c. daily intramuscularly for 6 days; and large doses of potassium salts.

\section{Comments}

This case of the infantile form of cerebro-macular degeneration is worth recording because it is the first case of its kind from Malaya in a Chinese infant. In the absence of a complete history, it is difficult to exclude the familial nature of the illness. Two other children in the same family have died, but it is not known of what they died. Although the age at which the first signs and symptoms manifested themselves is not clear and definite, the clinical features and course of the disease should be characteristic enough to make a clinical diagnosis possible but this was offset by the fact that this was a non-Hebraic case which confused the racial incidence and also by the fact that no such case had been seen before in Malaya. He was delivered normally at full term. He was admitted to hospital for convulsions when he was $13 \frac{1}{2}$ months old. But before this the mother had noticed that he had not been able to sit up by himself and that he had become less and less active as days passed on. After admission, it was noticed that there was marked muscular weakness and wasting, signs of visual failure ending in blindness and marked lack of mental development. An examination of the fundus revealed signs pathognomonic of the infantile form of cerebro-macular degeneration, a somewhat oval dark purplish-red spot at macular area on a milky bluish-white background. An additional feature in this case is a rapidly increasing hydrocephalus. He stayed in hospital for three months and five days and died when he was twenty months and twenty days old of terminal lobar pneumonia.

\section{Summary}

- 1. A case of the infantile form of cerebro-macular degeneration, otherwise known as Waren Tay-Sachs disease or amaurotic family idiocy, in a Chinese Hylam male infant is reported, the first of its kind from Malaya.

2. Due to an incomplete history, no history of consanguinity or of familial incidence was obtained.

3. The child was twenty months twenty days old when he died. 
4. Diagnosis was established from the progressive muscular weakness, lack of mental development and blindness with pathognomonic changes in the fundus.

In conclusion, I have to thank Dr. William Heng for assisting me with the notes of this case, Dr. Chew Poh Kuo for the original diagram of the appearance of the left fundus, and the Director of Medical Services, Singapore Union, for permission to publish this case.

\title{
REFERENCES
}

Baker, A. B. and Platou, E. (1938).-Arch. Path., Vol. XXV, p. 75.

Bielschowsky, M. (1920)-Jl.f. Psychol. u. Neurol., Vol. XXVI, p. 123. (1928). - Ibidem, Vol. XXXVI, p. 131.

CARTER (1894).-Arch. of Ophthal., New York, Vol. XXIII, p. 126.

HAMBURGER, R. (1927). -Jahrb. f. Kinderh. Berlin. Vol. CXVI, p. 41.

Kamel Yacoub (1938).-Jl. of Egypt Med. Assoc., Vol. XXI, p. 377.

KINGDON (1894). -Trans. Ophthal. Soc. U.K., p 14.

KuFs, H. (1933).-Zeitschr.f.d. ges. Neurol. u Psychist., Vol. CLV, p. 565.

MOTT (1907).-Arch. of Neurol., Vol. III, p. 218.

PICK, L. (1933).Amer. Jl. Med. Sc., Vol. CLXXXV, p. 601.

Poynton, Parsons and Holmes, Gordon (1906).-Brain, Vol. XXIX, p. 180.

SaChs, Bernard (1887).- Jl. of Nerve and Mental Dis., New York, Vol. XIV, p. 541.

(1896).-Ibidern., Vol. XXXI, p. 475

SchAFFER, K. (1935)-(1935).-Deutsche Zeitschr. f. Nervenh., Vol. CXXXV, p. 11 .

Slome. D. (1933).-Jl. Genetics, London, Vol. XXVII, p. 363.

SPIElmeyer, W. (1929).-Jl.f. Psychol. u. Neurol., Vol. XXXVIII, p. 120.

WAREN TAY (1850-1851).-Trans. Ophthal. Soc. U.K. Lond., Vol. I, p. 55.

\section{TECHNICAL IMPROVEMENTS IN THE DIATHERMY OPERATION FOR DETACHMENT OF THE RETINA}

\author{
BY
}

\author{
Prof. A. Kettesy \\ DEBRECEN, HUNGARY
}

THE diathermy operation for retinal detachment, in spite of its great development, still has such technical difficulties, which may be eliminated by improvement of the instruments used in the principal phase of the operation, the coagulative closing of the hole by the pointed perforating electrode.

There have been two main forms of perforating electrodes in use up to date : the needle, as described and used by Weve, Vogt; Szily-Machemer and others, and the nail of Safar and Arruga.

The drawback of the needle is that it has to be pulled out after every puncture. There arise leaking channels through the sclerotic and choroid from the beginning, with more or less continuous loss of inter-retinal fluid. Their number increases during the operation necessarily, hence the eye softens and the scleral surface 